Article

\title{
Membranous glomerulonephritis: a retrospective study on prognostic outcome
}

\author{
Sadiq Mu'azu Maifata ${ }^{1,2,3}$, Rafidah Hod ${ }^{2}$, Fadhlina Zakaria ${ }^{4}$ and Fauzah Abd Ghani ${ }^{1 *}$ \\ 1. Histopathology Unit, Department of Pathology, Faculty of Medicine and Health Science, \\ Universiti Putra Malaysia, Serdang, Selangor 43400, Malaysia; teemoh87@gmail.com \\ (S.M.M.); fauzah@upm.edu.my (F.A.G.)
}

2. Physiology Unit, Department of Anatomy, Faculty of Medicine and Health Science, Universiti Putra Malaysia, Serdang, Selangor; 43400, Malaysia; rafidahhod@upm.edu.my

3. Department of Physiology, Faculty of Basic Medical Science, College of Medicine, Federal University of Lafia, Lafia, Nasarawa 950102, Nigeria.

4. Nephrology Unit, Department of Medicine, Faculty of Medicine and Health Science, Universiti Putra Malaysia, Serdang, Selangor 43400, Malaysia; n_fadhlina@upm.edu.my

* Correspondence: fauzah@upm.edu.my; Tel.: +6013-6277576.

\section{Abstract:}

Background: Membranous glomerulonephritis (MGN) is one of the most common causes of nephrotic syndrome in non-diabetic adults, accounting for up to one-third of biopsy diagnostics in some regions. A watchful waiting strategy has been adopted to accurately assess the success of MGN. In this study, we predict prognostic risk factors for primary MGN patients for effective intervention and prognosis.

Materials and Methods: This is a retrospective study design involving 125 biopsy-proven MGN subjects on follow-up from January 2012 to October 2019 in Hospital Serdang and Hospital Kuala Lumpur, Malaysia.

Result and Conclusion: After the median follow-up of 36 (15.0-57.0) months, 26 (20.8\%) consisting of $17(13.6 \%)$ primary MGN and $9(7.2 \%)$ secondary MGN subjects achieved complete remission while $17(13.6 \%)$ and $10(8.0 \%)$ of primary and secondary MGN subjects respectively achieved spontaneous remission. Subjects with nephrotic range proteinuria have 2.917 odds more 
at risk of primary MGN while subjects with hypertension have 2.417 odds risk of primary MGN compared to those with no hypertension at presentation. Multiple logistic regression models retained only factors directly associated with MGN with only nephrotic range proteinuria associated with primary MGN. Those with nephrotic range proteinuria were 3.04 times the odds of primary MGN when compared with those without nephrotic syndrome $(95 \% \mathrm{C}$. I $=1.089$, 8.472).

The nephrotic syndrome could be used to determine the prognosis in patients with primary MGN especially those at risk of end-stage kidney disease.

Keywords: Membranous glomerulonephritis; remission; nephrotic syndrome; chronic kidney disease, end-stage kidney diseases.

\section{Introduction}

One of the leading causes of nephrotic syndrome in non-diabetic adults, accounting for up to one-third of biopsy diagnoses in some areas (1). The time frame between the manifestation of cancer and the diagnosis of MGN is between the ages of 52 and 65 years, respectively (2).

Patients may undergo remission or have chronic proteinuria without developing renal dysfunction or may develop end-stage kidney disease (ESKD). Thirty per cent renal survival was reported in patients who were not in remission, $100 \%$ in those who were in complete remission, and greater than $70 \%$ in those who were in partial remission $(3,4)$.

A watchful waiting strategy has been adopted to accurately assess the progress of MGN. This entails measuring urinary protein and creatinine clearance every 24 hours for at least 6 months and comparing the results to nephrotic range proteinuria levels (5).

At present, there is not enough data on the prognosis of patients with nephrotic syndrome secondary to membranous nephropathy. Nevertheless, reduction in proteinuria is related to achieving remission in primary MGN $(6,7)$. In addition, studies were conducted on the same 
patients to determine the prognosis using M-type phospholipase A2 receptors (M-PLA2R) and Thrombospondin domain-containing type 7 A (THSD7A) demonstrated a direct relationship with proteinuria (8). In this study, we predict prognostic risk factors for primary MGN patients for effective intervention. In addition, clinicians will benefit from this prediction tool in assessing the risk variables directly linked to primary MGN patients and determining who need more intensive therapies and regular follow-up.

\section{Materials and Method}

\subsection{Study design}

This is a retrospective study design involving biopsy-proven primary MGN on follow-up from January 2012 to October 2019 in Hospital Serdang and Hospital Kuala Lumpur, Malaysia. Ethical approval was obtained from the National Medical Research Register (NMRR--18-324544092). To ensure confidentiality of the data collected in the proforma, each subject was coded and blinded to its clinical data.

\subsection{Methodology}

\subsubsection{Data collection}

Information on patients' were obtained from the library information system in Hospital Serdang and Kuala Lumpur as shown in Figure 1. Full clinical work-up and clinical correlation were used to classify the biopsy as either primary or secondary MGN. Clinical parameters were used to rule out secondary involvement (MGN with associated chronic conditions such as hepatitis B virus infection, diabetes nephropathy, malignancy, and lupus nephritis type V). In contrast, those with no known associated conditions were considered primary MGN.

One hundred and twenty-five patients were diagnosed with MGN from January 2012 to October 2019 at hospitals in Serdang and Kuala Lumpur. General information such as age, sex and contacts of subjects were obtained from the hospitals' databases. 


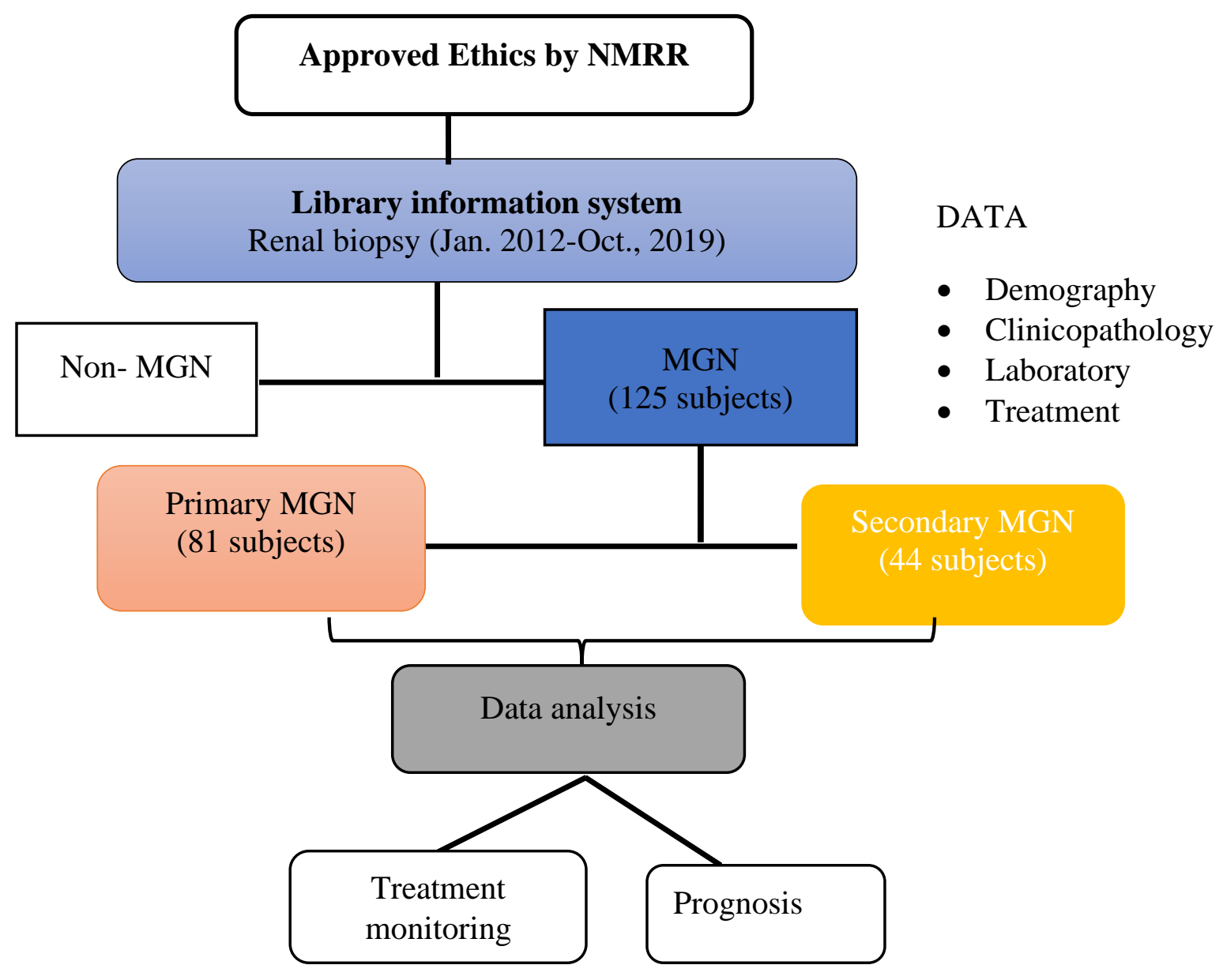

Figure 1: Flow chart of events from ethical approval to data analysis.

\subsubsection{Cut-off points value for laboratory parameters}

Complete remission and no remission were defined as urinary protein to creatine index (UPCI) of $0.03 \mathrm{~g} / \mathrm{mmol}$ and $>0.03 \mathrm{~g} / \mathrm{mmol}$, respectively, according to Kidney Disease Improving Global Outcome (KDIGO) (9). Serum albumin levels of 35g/L were considered low, while serum urea and creatinine levels of 2.76-8.07mmol/L and 44-80 mol/L, respectively. The Estimated Glomerular Filtration Rate (eGFR) was defined as follows: > 90, 60-89, 45-59, 30-44, 15-29 and 
$15 \mathrm{~mL} / \mathrm{min} / 1.73 \mathrm{~m}^{2}$ for normal, chronic kidney disease stage I (CKD 1), CKD 2, CKD 3, CKD 4 and CKD 5 respectively, calculated using the CKD-EPI Creatinine 2009 Equation.

\subsection{Data Analysis}

The data was analysed using IBM SPSS statistics for the MacBook (SPSS version 25.0). Normally distributed continuous variables were expressed as mean SD, while non-normally distributed variables were expressed as median (interquartile). Simple and multiple regression analyses were conducted to determine the factors associated with MGN, validated by the ROC curve. At $\mathrm{p}<0.05$, differences were considered statistically significant.

\section{Results}

\subsection{General characteristics of subjects}

3.1.1 Socio-demographic characteristics of subjects.

The median age at diagnosis was 45.0 (29.5-58.5) years. Figure 2 shows that primary MGN is the most common, accounting for 81 cases (63.2\%) of all MGN, while lupus nephritis was the most common cause of secondary MGN, responsible for $23.2 \%$ of all MGN. Other causes of secondary MGN include hepatitis B virus infection (4\%), hepatitis C virus infection (0.4\%), diabetes mellitus (1.6\%), malignancy (3.6\%) and others (4\%) like sarcoidosis, rheumatoid arthritis, and drugs.

The subjects were divided into different age groups, with the majority of them (34 of 125$) \leq 30$ years old, most of whom were of secondary MGN. This was followed by those in the age group of 51-60 (27 of 125), who were mostly of primary MGN. Primary MGN was more common among male subjects (a male to female ratio of 1.6:1) whereas secondary MGN was more common among female subjects (male: female ratio of 1:3). Primary MGN was more common among the Malay population of 40 (32.0\%), followed by the Chinese ethnic group of 22 (17.6\%) 


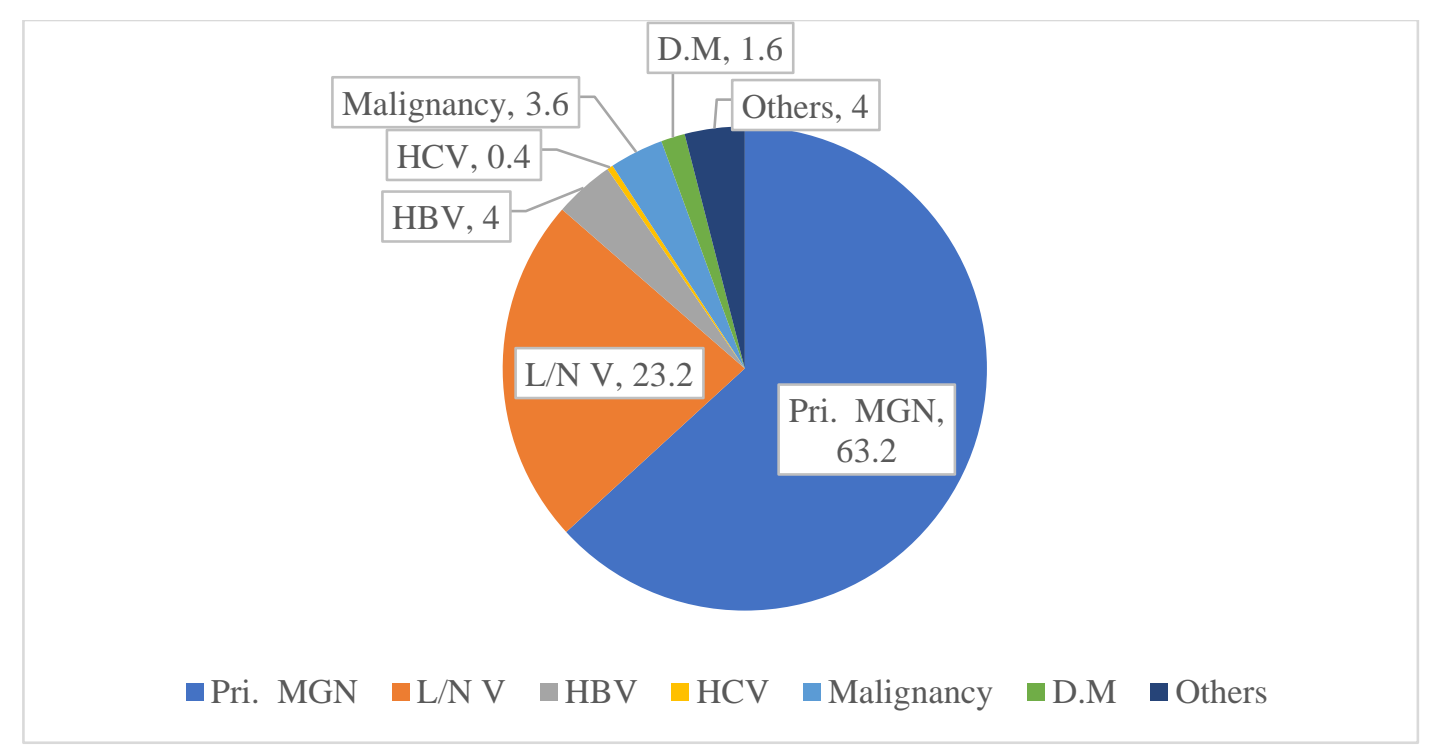

Figure 2: Percentages of primary MGN and secondary MGN with a detailed aetiological proportion.

Table 1 depicts a strong association between MGN and age at diagnosis. In contrast to primary MGN, which is associated with subjects aged 50-60 years, secondary MGN is associated with subjects aged $\leq 30$ years $\left(X^{2}=19.940, p=0.001\right)$. In addition, MGN status is significantly associated with gender in which there is a significantly higher proportion of males $(82 \%)$ with primary MGN in contrast with a higher proportion of $51.6 \%$ of females with secondary MGN $\left(\mathrm{X}^{2}\right.$ $=14.391, \mathrm{p}<0.001)$. Secondary MGN is more associated with Malay ethnic group 34 (45.9\%). Primary MGN is significantly associated with other ethnic groups (86.4\%) followed by the Chinese population $(75.9 \%)$ and Malay descent $(54.1 \%)\left(X^{2}=9.787, p=0.007\right)$. 
Table 1: Association between socio-demographic factors and MGN

\begin{tabular}{|c|c|c|c|c|}
\hline Variables & $\begin{array}{l}\text { Primary MGN } \\
n=81(\%)\end{array}$ & $\begin{array}{l}\text { Secondary MGN } \\
n=44(\%)\end{array}$ & $\mathbf{X}^{2}$ & *p-value \\
\hline Age at Diagnosis (years) & & & 19. & $0.001 *$ \\
\hline$\leq 30$ & $13(38.2)$ & $21(61.8)$ & & \\
\hline $31-40$ & $13(65.0)$ & $7(35.0)$ & & \\
\hline $41-50$ & $10(58.9)$ & $7(41.1)$ & & \\
\hline $51-60$ & 24(88.9) & $3(11.1)$ & & \\
\hline $61-70$ & 11(73.3) & $4(26.7)$ & & \\
\hline$>70$ & $10(83.3)$ & $2(16.7)$ & & \\
\hline Gender: & & & 14.391 & $<0.001 *$ \\
\hline Male & $50(82.0)$ & $11(18.0)$ & & \\
\hline Female & $31(48.4)$ & $33(51.6)$ & & \\
\hline Ethnicity: & & & 9.787 & $0.007 *$ \\
\hline Malay & $40(54.1)$ & $34(45.9)$ & & \\
\hline Chinese & $22(75.9)$ & $7(24.1)$ & & \\
\hline Others & $19(86.4)$ & $3(13.6)$ & & \\
\hline
\end{tabular}

Categorical variables were expressed in frequencies (percentage) and compared by chi-square value $\left(X^{2}\right)$, significance level $\mathrm{p}<0.05^{*}$

3.1.2. Clinico-pathological parameters of subjects $(n=125)$ at presentation

Nephrotic range proteinuria and haematuria were seen among 63 (72.4\%) and $14(66.7 \%)$ primary MGN subjects respectively. Table 2 shows 47 (74.6\%) primary MGN and 16 (25.4\%) secondary MGN presented with hypertension. The serum urea at presentation was high among $20.0 \%$ and $6.4 \%$ of subjects with primary and secondary MGN respectively, while 67 of the 125 subjects presented with high serum creatinine levels, most of whom (53 of 67) belonged to primary MGN. Low serum albumin levels at presentation were seen in $45.6 \%$ of primary MGN subjects and 20.0\% of secondary MGN subjects. For eGFR level at presentation, 26 of the 125 
subjects had a moderately high level of eGFR while 16 of the 125 had a severely high level of eGFR, whereas the UPCr Index at presentation was very high in $63 \%$ and $16 \%$ of subjects with primary and secondary MGN.

Nephrotic range proteinuria is found to be more significantly associated with primary MGN $(72.4 \%)$ than secondary MGN $(27.6 \%)\left(\mathrm{X}^{2}=7.273, \mathrm{p}=0.007\right)$, whereas haematuria $(66.7 \%)$ is found to be more associated with primary $\operatorname{MGN}\left(\mathrm{X}^{2}=5.351, \mathrm{p}=0.025\right)$. Likewise, hypertension and serum creatinine are more associated with primary MGN $\left(\mathrm{X}^{2}=7.273, \mathrm{p}=0.021\right)$ and $\left(\mathrm{X}^{2}=\right.$ $12.953, \mathrm{p}=0.001)$ respectively. Compared to secondary MGN, moderately and severely low eGFR are more significantly associated with primary $\operatorname{MGN}\left(\mathrm{X}^{2}=8.128, \mathrm{p}=0.043\right)$. 
Table 2: Association between clinicopathological data and MGN

\begin{tabular}{|c|c|c|c|c|}
\hline Variables & $\begin{array}{l}\text { Primary MGN } \\
\mathrm{n}=\mathbf{8 1}(\%)\end{array}$ & $\begin{array}{l}\text { Secondary MGN } \\
n=44(\%)\end{array}$ & $\mathbf{X}^{2}$ & p-value \\
\hline Nephrotic range proteinuria: & & & 7.273 & $0.007 *$ \\
\hline Absent & $18(47.4)$ & $20(52.6)$ & & \\
\hline present & $63(72.4)$ & $24(27.6)$ & & \\
\hline Haematuria: & & & 5.351 & $0.025 *$ \\
\hline Absent & $67(64.4)$ & $37(35.6)$ & & \\
\hline Present & $14(66.7)$ & $7(33.3)$ & & \\
\hline Hypertension: & & & 7.273 & $0.021 *$ \\
\hline Absent & $34(54.8)$ & $28(45.2)$ & & \\
\hline Present & $47(74.6)$ & $16(25.4)$ & & \\
\hline Albumin (g/L): & & & 2.321 & 0.128 \\
\hline Low & $57(69.5)$ & $25(30.5)$ & & \\
\hline Normal & $24(55.8)$ & $19(44.2)$ & & \\
\hline Serum creatinine $(\mu \mathrm{mol} / \mathrm{L})$ : & & & 12.953 & $<0.001 *$ \\
\hline Normal & $28(48.3)$ & $30(51.7)$ & & \\
\hline High & $53(79.1)$ & $14(20.9)$ & & \\
\hline Serum urea (mmol/L): & & & 2.360 & 0.124 \\
\hline Normal & $56(60.9)$ & $36(39.1)$ & & \\
\hline Abnormal & $25(75.8)$ & $8(24.2)$ & & \\
\hline UPCr Index (g/mmol): & & & 5.223 & 0.073 \\
\hline Normal & $10(45.5)$ & $12(54.5)$ & & \\
\hline Moderately High & $20(62.5)$ & $12(37.5)$ & & \\
\hline Severely High & $51(71.8)$ & $20(28.2)$ & & \\
\hline $\operatorname{eGFR}\left(\mathrm{mL} / \mathrm{min} / 1.73 \mathrm{~m}^{2}\right)$ : & & & 8.128 & $0.043 *$ \\
\hline Normal & $30(51.7)$ & $28(48.3)$ & & \\
\hline Mild & $19(76.0)$ & $6(24.0)$ & & \\
\hline Moderate & $20(76.9)$ & $6(23.1)$ & & \\
\hline Severe & $12(75.0)$ & $4(25.0)$ & & \\
\hline
\end{tabular}


Categorical variables were expressed in frequencies (percentage) and compared by chi-square $\left(\mathrm{X}^{2}\right)$, urine protein creatinine index (UPCr Index), estimated Glomerular Filtration Rate (eGFR) normal- $=\geq 90$, mild $=60-89\left(\mathrm{~mL} / \mathrm{min} / 1.73 \mathrm{~m}^{2}\right)$, moderate $=30-59\left(\mathrm{~mL} / \mathrm{min} / 1.73 \mathrm{~m}^{2}\right)$, high $=<30$ $\left(\mathrm{mL} / \mathrm{min} / 1.73 \mathrm{~m}^{2}\right)$, significant level $p<0.05^{*}$

\subsection{The outcome of subjects $(n=125)$ at the end of follow-up}

Table 3 shows the outcome of subjects at the end of follow-up. After a median follow-up of 36 (15.0-57.0) months, 26 (20.8\%) consisting of 17 (13.6\%) primary MGN and 9 (7.2\%) secondary MGN subjects achieved complete remission with immunosuppressive therapy while 17 (13.6\%) and $10(8.0 \%)$ of primary and secondary MGN subjects respectively achieved complete remission without immunosuppressive therapy. Of the total subjects that achieved partial remission, 47 (36.6\%), 26 (20.8\%) were of the primary type, while 21 (16.8\%) belonged to the secondary MGN. In addition, $21(16.8 \%)$ and 4 (3.2\%) belonged to both primary and secondary MGN, yet to achieve remission.

Primary MGN subjects were responsible for 55 (44.0\%) of the high-risk eGFR 88 (70.4\%) while the remaining were due to secondary MGN.

Table 3: Subjects $(n=125)$ outcome at the end of follow-up

\begin{tabular}{lllll}
\hline Variable & \multicolumn{2}{c}{ Primary } & \multicolumn{2}{c}{ Secondary } \\
& $\begin{array}{l}\text { Frequency/ } \\
\text { Median }\end{array}$ & $\begin{array}{l}\text { Percentage(\%)/ } \\
\text { interquartile }\end{array}$ & $\begin{array}{l}\text { Frequency/ } \\
\text { Median }\end{array}$ & $\begin{array}{l}\text { Percentage(\%)/ } \\
\text { interquartile }\end{array}$ \\
\hline $\begin{array}{l}\text { Follow-up(months) } \\
\text { Remission }\end{array}$ & 39.0 & $17.5-59.5$ & 27.5 & $13.0-49.8$ \\
Complete (with IT) & 17 & 13.6 & 9 & 7.2 \\
Complete (without IT) & 17 & 13.6 & 10 & 8.0 \\
Partial & 26 & 20.8 & 21 & 16.8 \\
No remission & 21 & 16.8 & 4 & 3.2 \\
\hline
\end{tabular}

Immunosuppressive therapy (IT)

\subsection{Risk factors for primary $M G N$}

Table 4 shows the results of a multivariate logistic analysis of factors associated with MGN among subjects on follow-up at Hospital Serdang and Hospital Kuala Lumpur. Following 
univariate logistic regression, the multiple logistic regression was done to determine the factors that are directly linked to primary MGN. In this case, only nephrotic range proteinuria was directly associated with primary MGN. Therefore, subjects with nephrotic range proteinuria had 3.04 times the odds of primary MGN compared to those without nephrotic range proteinuria $(95 \%$ C. I = 1.089, 8.472). 
Table 4: Multivariate logistic regression analysis of factors associated with primary MGN.

\begin{tabular}{|c|c|c|c|c|c|}
\hline Variables & B -Coefficient & S.E & AOR & C. I (95\%) & p-value \\
\hline Age at diagnosis: & & & & & 0.175 \\
\hline$\leq 30$ & 0.449 & 0.699 & 1.57 & $0.398-6.164$ & 0.521 \\
\hline $31-40$ & 0.301 & 0.686 & 1.35 & $0.352-5.185$ & 0.661 \\
\hline $41-50$ & 1.756 & 0.758 & 5.79 & $1.308-25.593$ & 0.021 \\
\hline $51-60$ & 1.324 & 0.805 & 3.76 & $0.776-18.203$ & 0.100 \\
\hline $61-70$ & 1.458 & 0.984 & 4.30 & $0.624-29.561$ & 0.139 \\
\hline \multicolumn{6}{|l|}{$\geq 70$} \\
\hline \multicolumn{6}{|l|}{ Gender: } \\
\hline Male & & & 1.00 & & \\
\hline Female & -0.935 & 0.485 & 0.39 & $0.152-1.015$ & 0.054 \\
\hline Ethnicity: & & & & & 0.099 \\
\hline Others & & & 1.00 & & \\
\hline Malay & -1.695 & 0.867 & 0.18 & 0.034-1.004 & 0.051 \\
\hline Chinese & -0.952 & 0.952 & 0.39 & $0.060-2.494$ & 0.317 \\
\hline \multicolumn{6}{|c|}{ Nephrotic syndrome: } \\
\hline Absent & & & 1.00 & & \\
\hline Present & 1.111 & 0.523 & 3.04 & $1.089-8.472$ & $0.034^{*}$ \\
\hline \multicolumn{6}{|l|}{ Hypertension } \\
\hline Absent & & & 1.00 & & \\
\hline Present & -0.089 & 0.501 & 1.09 & $0.410-2.910$ & 0.858 \\
\hline
\end{tabular}

S. E $=$ standard error, C. I= confidence interval, AOR= Adjusted Odd Ratio, significant value < $0.05^{*}$

\section{Discussion}

\subsection{General characteristics of the subjects}

The proportion of primary and secondary MGN varies from one region to another, most reported within $70-80 \%$ and $20-30 \%$ for primary and secondary MGN respectively (10-14). In addition, the male to female for MGN was 2-3:1 in favour of men in most studies. These values are slightly in contrast with the values obtained from this study, which put the proportion of MGN at $63.4 \%$ and $36.6 \%$ for both primary and secondary MGN, respectively, and a male to female ratio of 1:1.1 with a slight female predominant. The reason may not be unconnected to the high 
prevalence of lupus nephritis in Malaysia (15). While primary MGN was thought to be common among Caucasians and Southeast Asians globally, it was reported more frequently among Malay and Chinese in Malaysia $(15,17-19)(5,16)$.

Studies have shown that patients with advanced age, low albumin, haematuria, abnormal serum creatinine, serum urea and eGFR are at risk of progressing to ESKD (24-26). Like other studies $(18,20)$, this study also demonstrated that nephrotic syndrome was the most common presentation among adults with MGN. Haematuria was also a common presentation, especially among individuals with the nephritic-nephrotic syndrome (21-23), while hypertension was seen mostly as a complication when there is renal compromise or in the acute form of MGN, occurring in up to $30 \%$ of cases $(9,22)$ similar as in this study where it was reported in $37.6 \%$ of subjects with primary MGN.

It is important to note that the urine protein creatinine index (UPCr Index) is considered a prognostic laboratory parameter for MGN because the nephrotic syndrome is the most common presentation and, therefore, a low UPCr Index is associated with good prognosis (remission) and vice versa $(9,27)$.

Treatment of MGN patients depends on the type and presentation. Patients with lower eGFR and UPCr Index were considered low risk and therefore benefited from supportive therapy or watchful waiting techniques (5). Immunosuppressive therapy is initiated only when there is a high risk of progression to ESKD, as evidenced by a creatinine level doubling within 6 months of presentation, a UPCr Index $>8 \mathrm{~g} / \mathrm{g}$, and persistence proteinuria (28). Hence, the reason why most of the subjects in this study received either supportive therapy or nothing. Furthermore, it is important to delay the immunosuppressive therapy by 6 months since it was reported that one- 
third of patients with primary MGN can achieve remission within 6 months. This claim can be supported by this study where $21.6 \%$ of the total 125 subjects achieved remission without any immunosuppressive therapy and another study by Perrine Jullien, et al., (2017) where 22\% achieved spontaneous remission (28).

\subsection{Predictors of $M G N$}

Although most of the clinical presentations of MGN (especially primary MGN) are not specific, there are some specific clinical presentations, including laboratory parameters associated with the severity of kidney disease as mentioned earlier. Nephrotic syndrome, especially in adults, is found to be a major risk factor for the primary MGN in this study. The finding supported the idea that nephrotic syndrome is the most common symptom and is also linked to remission (6).

\section{Conclusions}

Nephrotic syndrome is the most common presentation in primary MGN and could be used to determine the prognosis in patients with primary MGN. This will assist in early intervention, thereby preventing or reducing the rate of progression of primary MGN patients to ESKD.

\section{Limitation of the studies}

The study is retrospective in nature, which makes access to certain information such as survival analysis very difficult since the follow-up period was not uniform.

\section{Author Contributions:}

The conceptualization of this study was done by Sadiq Mu'azu Maifata and Fauzah Abd Ghani; methodology, Sadiq Mu'azu Maifata and Fauzah Abd Ghani; validation, Nor Fadhlina Zakaria., Fauzah Abd Ghani and Rafidah Hod; formal analysis, Sadiq Mu'azu Maifata; investigation, Nor Fadhlina and Sadiq Mu'azu Maifata; resources, Fauzah Abd Ghani; data curation, Sadiq Mu'azu Maifata.; writing — original draft preparation, Sadiq Mu'azu Maifata; writing—review and editing, Nor Fadhlina Zakaria, Rafidah Hod and Fauzah Abd Ghani; visualization, Sadiq Mu'azu 
Maifata; supervision, Fauzah Abd Ghani, Rafidah Hod and Nor Fadhlina Zakaria; project administration, Fauzah Abd Ghani; funding acquisition, Fauzah Abd Ghani and Nor Fadhlina Zakaria.

8. Acknowledgements: Grants from UNIVERSITI PUTRA MALAYSIA funded this research.

9. No conflict of interest and the funders had no role in the design of the study; in the collection, analyses or interpretation of data, in the writing of the manuscript or in the decision to publish the results.

\section{References}

1. Fogo AB, Lusco MA, Najafian B, Alpers AC. AJKD Atlas of Renal Pathology: Membranous Nephropathy. Am J Kidney Dis. 2015;66(3):e15.

2. Bjørneklett R, Vikse BE, Svarstad E, Aasarød K, Bostad L, Langmark F et al. Long-term risk of cancer in membranous nephropathy patients. Am J Kidney Dis. 2007;50(3):396403.

3. Bomback, AS. Management of Membranous Nephropathy in the PLA2R Era. Clin J Am Soc Nephrol. 2018;13:784-6.

4. Troyanov S, Wall CA, Miller JA, Cattran, DC. Idiopathic membranous nephropathy: definition and relevance of a partial remission. Kidney Int. 2004;66:1199-205.

5. Cattran DC \& Brenchley P. Membranous nephropathy: thinking through the therapeutic options. Nephrol Dial Transplant. 2017;32(1):22-9.

6. Polanco N, Gutierrez E, Covarsi A, Ariza F, Carreno A, Vigil A, et al. Spontaneous remission of nephrotic syndrome in idiopathic membranous nephropathy. J Am Soc Nephrol [Internet]. 2010;21(4):697-704. Available from:

http://www.jasn.org/cgi/doi/10.1681/ASN.2009080861

7. McQuarrie EP, Stirling CM, Geddes CC. Idiopathic membranous nephropathy and nephrotic syndrome: Outcome in the era of evidence-based therapy. Nephrol Dial Transplant. 2012;27(1):235-42.

8. Maifata SM, Hod R, Zakaria F, Ghani FA. Role of serum and urine biomarkers (PLA2R and THSD7A) in diagnosis, monitoring and prognostication of primary membranous glomerulonephritis. Biomolecules. 2020;10(2). 
9. Cattran DC, John, FH, Cook, T, Hong LZ, Fervenza FC, Mezzano SA, et al. Kidney disease: improving global outcomes (KDIGO) glomerulonephritis workgroup. KDIGO clinical practice guideline for glomerulonephritis. Kidney Int Suppl. 2012;2:139-274.

10. Nasr SH, Said SM, Valeri AM, Stokes MB, Masani NN, D’Agati VD, et al. Membranous glomerulonephritis with ANCA-associated necrotizing and crescentic glomerulonephritis. Clin J Am Soc Nephrol. 2009;4(2):299-308.

11. Cattran DC \& Brenchley P. Membranous nephropathy: Integrating basic science into improved clinical management. Kidney Int. 2017;566-74.

12. William CG. Primary Membranous Nephropathy. Clin J Am Soc Nephro. 2017;12(6):983-97.

13. Raza A \& Aggarwal, S. Glomerulonephritis, Membranous. StatPearls [Internet] Treasure Isl StatPearls Publ. 2018.

14. Yahya R, Jazilah W, Ismail W, Shaariah W. 5TH REPORT OF THE MALAYSIAN REGISTRY of RENAL BIOPSY 2012. 2014;19-25.

15. Zhou Q, Yang X, Wang M, Wang H, Zhao J, Bi Y, et al. Changes in the diagnosis of glomerular diseases in east China: a 15-year renal biopsy study. Ren Fail [Internet]. 2018;40(1):657-64. Available from: https://doi.org/10.1080/0886022X.2018.1537930

16. Yokoyama H, Taguchi T, Sugiyama H, Sato H. Membranous nephropathy in Japan: Analysis of the Japan Renal Biopsy Registry (J-RBR). Clin Exp Nephrol. 2012 Aug;16(4):557-63.

17. Keng-Thye W, Choong-Meng C, Lim C, Choo J, Chin YM, Wei Ling WT, et al. Changes in primary glomerulonephritis in Singapore over four decades. Clin Nephrol. 2019;91:155-61.

18. Xiaofan H, Jing X, Chenni G, Yifan W, Xialian Y, Li L, et al. New risk score for predicting progression of membranous nephropathy. J Transl Med [Internet]. 2019;17(1):1-7. Available from: https://doi.org/10.1186/s12967-019-1792-8

19. Matsukura H. Gross hematuria as an unusual manifestation of membranous nephropathy. Japanese J Pediatr Nephrol. 2008;21(2):91-4.

20. Rosai and Ackerman's Surgical Pathology 10th Ed. In: Rosai and Ackerman's Surgical Pathology. 2011.

21. Maifata SM, Hod R, Zakaria F, Ghani FA. Primary membranous glomerulonephritis: The role of serum and urine biomarkers in patient management. Biomedicines. 2019;7(4), 86.

22. Ihm C-G. Hypertension in Chronic Glomerulonephritis. Korean Soc Electrolyte Metab. 
$2015 ; 13: 41-5$.

23. Huh H, Lee H, Lee JP, Kim DK, Oh S, Oh YK, et al. Factors affecting the long-term outcomes of idiopathic membranous nephropathy. BMC Nephrol. 2017;18(1):4-11.

24. Pourcine F, Dahan K, Mihout F, Cachanado M, Brocheriou I, Debiec H, et al. Prognostic value of PLA2R autoimmunity detected by measurement of anti-PLA2R antibodies combined with detection of PLA2R antigen in membranous nephropathy: A single-centre study over 14 years. PLoS One. 2017;12(3):1-18.

25. Reichert LJ, Koene RA, Wetzels JF. Prognostic factors in idiopathic membranous nephropathy. Am J Kidney Dis. 1998;31(1):1-1.

26. Yamaguchi M, Ando M, Yamamoto R, Akiyama S, Kato S, Katsuno T, et al. Patient age and the prognosis of idiopathic membranous nephropathy. PLoS One. 2014;9(10):1-9.

27. Clase C. renal failure(Chronic). Clin Evid (Online). 2009;10:2004.

28. Jullien P, Polski BS, Maillard N, Thibaudin D, Laurent B, Ollier E, et al. Antiphospholipase A2 receptor antibody levels at diagnosis predicts spontaneous remission of idiopathic membranous nephropathy. Clin Kidney J. 2017;10(2):209-14. 